\title{
PRACTICING GeOPHYSICS
}

\section{Case History}

\section{Case history of combined airborne time-domain electromagnetics and power-line field survey in Chibougamau, Canada}

\author{
Marc A. Vallée ${ }^{1}$, Richard S. Smith², and Pierre Keating ${ }^{3}$
}

\begin{abstract}
Exploration for volcanogenic massive sulfides requires good geologic understanding. Geologic knowledge often is limited by a lack of outcrops. This is especially true in Canada under residual glacial covers. Geologic information must therefore be complemented by information obtained using means such as geophysical and geochemical observations. Electromagnetic (EM) methods extend lithological understanding to depths beyond the overburden. Massive sulfides are highly conductive and, depending on their depth and volume, may be detected easily by airborne EM surveys. They are more often equant than graphitic sediments, which typically have longer strike length. Current EM
\end{abstract}

techniques that identify massive sulfides operate in the frequency or time domain, the latter being more common. Additional information can be provided by using power-line fields as a source of EM signals when the powerlines are appropriately located in the area of interest. We have worked in an active exploration area near Chibougamau, Canada, known for a large occurrence of massive sulfide deposits. The geology is a sequence of volcanic formations with felsic and mafic intrusions. Our magnetic technique responded well to mafic rocks. An airborne time-domain EM survey mapped localized and intrasedimentary conductors in that area. We learned in our study that power-line EM fields can be used to map large-extent conductive formations and narrow geologic faults.

\section{INTRODUCTION}

Volcanogenic massive sulfide (VMS) deposits are conductive and are important targets for geophysical mineral exploration, particularly using electromagnetic (EM) methods. Partly because of VMS active and modern analogs, VMS deposits are well understood (Gibson et al., 2007). However, the geology of VMS deposits and the complexity of their composition mean that geophysical methods used for VMS exploration cannot be used blindly.

A good example of combining geology, geochemistry, and geophysics for VMS exploration is provided by the exploration history of the Noranda district (Boldy, 1979), where several VMS deposits were found from 1920 to 2003 . Geophysical methods were instrumental in discovering many of these deposits, starting from the dipneedle magnetometer used to discover the Aldermac deposit in 1925 to the helicopter-borne frequency-domain EM system (Dighem) that led to the New Insco discovery in 1973. The more recent West Ansil discovery (2003) resulted from the use of a computer-aided geological, geochemical, and geophysical compilation of the Noranda district, using sophisticated 3D computer visualization tools and a refined genetic model for VMS deposits (Martin and Masson, 2005). This illustrates the importance of using all available information in conducting VMS exploration.

Presented at the 78th Annual Meeting, SEG.

This paper was submitted to the new journal experiment.

Manuscript received by the Editor 16 April 2009; revised manuscript received 28 July 2009; published online 23 March 2010.

${ }^{1}$ Fugro Airborne Surveys, Ottawa, Canada. E-mail: mvallee@ fugroairborne.com.

${ }_{2}^{2}$ Formerly Fugro Airborne Surveys, Ottawa, Canada. Presently Laurentian University, Sudbury, Canada. E-mail: rssmith@ @laurentian.ca.

${ }^{3}$ Geological Survey of Canada, Ottawa, Canada. E-mail: pkeating@nrcan.gc.ca. (C) 2010 Society of Exploration Geophysicists. All rights reserved. 
Gibson et al. (2007) lay out rules for VMS exploration that can be summarized in four general observations. First, deposits commonly occur in clusters that define VMS districts. Second, large deposits ( $>50$ or 100 million tons) are uncommon. Third, polymetallic and precious-metal-rich deposits can be related to specific regional, local, and composition characteristics. Finally, metamorphosed deposits found in Archean or Proterozoic terranes tend to have coarsergrained sulfides, and base-metal recovery is better than in nonmetamorphosed deposits.

One of the latest tools for VMS exploration includes the MEGATEM $^{\mathrm{II}}$ airborne time-domain electromagnetic (ATDEM) system. This system is a fixed-wing system that includes a fixed transmitter loop located on a large aircraft (DASH-7) and a threecomponent magnetic receiver located in a towed sensor, or bird (Smith et al., 2003). The geometry of this system is illustrated in Figure 1 . The dipole moment of the transmitter is nearly one million ampere-meters ${ }^{2}$. The large transmitter-receiver separation allows the system to be sensitive to conductors located at relatively large distances below the aircraft. The transmitter signal is a half-sine pulse of alternative polarity repeated at a fixed base frequency. The receiver samples the detected signal at logarithmic distributed time gates during on and off times (see Figure 2).

Near power lines, the received signal is affected by the EM fields of the power lines and the earth's response to these fields. In North America, power lines radiate at $60-\mathrm{Hz}$-and-higher harmonics. The effect of the power line on the ATDEM data is minimized by transmitting the ATDEM signal at base frequencies of 150,90 , or $30 \mathrm{~Hz}$, (where the power line has minimal signal) and by applying stacking techniques that effectively remove the $60-\mathrm{Hz}$-and-higher harmonic responses. The power-line signal is recorded at the receiver along with the ATDEM signal and can be extracted by filtering.

Power-line sources can also be used in airborne resistivity mapping, as shown by Labson and Medberry (1989), who measure power-line fields up to $20 \mathrm{~km}$ from a power-line source. They calculate apparent-resistivity variations from the earth's response to the power-line fields and relate the variations to time-domain EM anomalies detected by an ATDEM system and to magnetic features in an area of thick overburden. The power-line source and ATDEM transmitter have different geometries and frequencies, so EM fields for these two sources have different geometries and can detect different con-

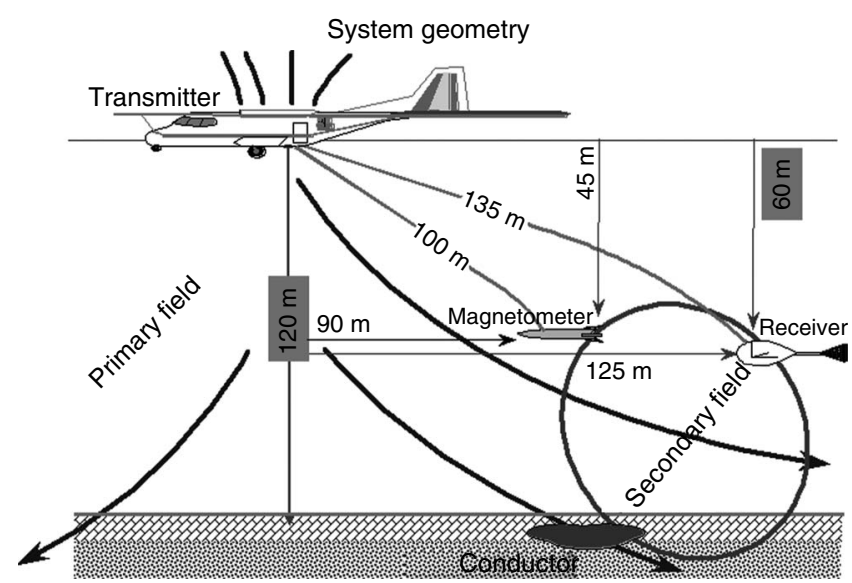

Figure 1. Schematic of the ATDEM system. The receiver is housed in a bird (towed sensor) $135 \mathrm{~m}$ below and $60 \mathrm{~m}$ behind the transmitter. There is also a towed magnetometer sensor for measuring the intensity of the earth's magnetic field. ductors. In an area where both signals can be collected and processed, it is expected that the power-line field measurements will provide complementary information to the data collected by the ATDEM system and will help in exploring for VMS mineralization.

In this paper, we illustrate the enhancement of ATDEM information with power-line field measurements using a survey with VMS exploration potential. First, we discuss the nature of the power-line and ATDEM fields. Then, we present the geology of the study area. Finally, we jointly analyze the results of an ATDEM survey and power-line field measurements.

\section{POWER-LINE AND ATDEM FIELDS}

Power-line source fields and source fields generated by the ATDEM system have different characteristics, and a given geologic conductor will generate different responses to both types of source fields. The field from a power line is more complex than the field from a line source. The field from a line source falls off as the inverse of the distance from the line, with some exponential decay function of frequency and ground conductivity. The field from a power line, comprised of several spaced current lines with distinct phases, depends on the phase and distance difference between the current lines
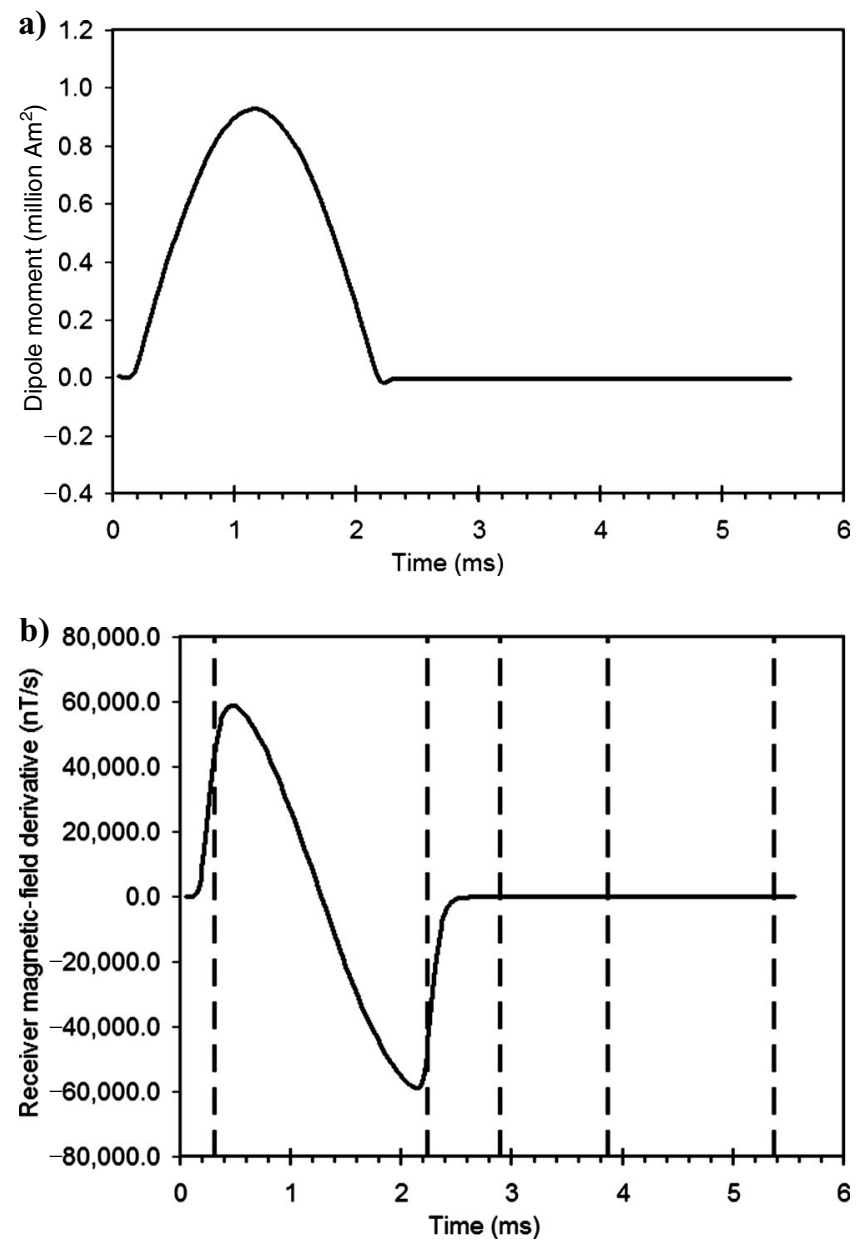

Figure 2. One half-cycle of the ATDEM waveform with windows and delay times: (a) transmitter moment waveform; (b) receiver of the horizontal $(X$-coil) component. In $(b)$, vertical dashed lines indicate the position of the first, fifth, tenth, fifteenth, and twentieth windows (note the nonlinear distribution). 
and on the height of the various lines of current above the ground.

In practice, these fields can be detected up to $20 \mathrm{~km}$ from their source (Labson and Medberry, 1989). The field of an aircraft loop can be approximated, at some distance, as the field of a vertical magnetic dipole. The magnetic field is vertical directly under the loop and usually has a strong horizontal component close to the receiver, which is towed behind and below the aircraft. The frequency range of the two sources are similar but not identical: the power-line fundamental frequency of $60 \mathrm{~Hz}$ is in the range of the lowest frequency ( 30 or $90 \mathrm{~Hz}$ ) transmitted by the ATDEM transmitter. The geometry of these fields dictates the type of geologic targets they can detect. An ATDEM system is designed to respond mostly to local conductors; power-line fields are expected to respond to large and possibly deep conductors.

\section{PRESENTATION OF POWER-LINE FIELDS}

The power-line responses are extracted from the ATDEM receiver data sampled at a rate of about $24 \mathrm{kHz}$. We estimate the intensity of the three orthogonal components at the power-line frequency and its higher-order harmonics. As a first approximation, power-line fields are considered as uniform at large distances from the source. Various quantities (field amplitude, phase, ratios, etc.) can be used to display power-line responses.

Labson and Medberry (1989) suggest estimating the apparent conductivity from the ratio of the horizontal derivatives to the vertical power-line field. Apparent conductivity is an estimate of the equivalent conductivity of a half-space, developed by Schmucker (1973) according to several approximations. First, the earth's surface is taken to be flat. Second, the electrical field is assumed horizontal over the surface of the ground. Third, the dimensions of variations in the source field are assumed to be much larger than the area investigated, which implies that the source is quasi-static. Fourth, the nearest vertical boundary is farther than the skin depth,

$$
C(\omega)=\sqrt{\frac{1}{\omega \mu_{0} \sigma}},
$$

where $\omega$ is the radial frequency, $\mu_{0}$ is the magnetic permeability, and $\sigma$ is the conductivity of the equivalent half-space. These conditions are illustrated in Figure 3. When they are satisfied, the magnetic fields located above the ground, which are space and frequency dependent, satisfy

$$
H_{z}=C(\omega)\left(\frac{\partial H_{x}}{\partial x}+\frac{\partial H_{y}}{\partial y}\right) .
$$

From equations 1 and 2, it is possible to estimate apparent conductivity, the conductivity of an equivalent half-space. The solution is

$$
\sigma_{a}=\frac{1}{\omega \mu_{0}|C|^{2}},
$$

where

$$
C=\frac{H_{z}}{\frac{\partial H_{x}}{\partial x}+\frac{\partial H_{y}}{\partial y}} .
$$

An alternative way to estimate apparent conductivity is to separate a residual from the power-line primary field, which decays away from the power line. This alternative technique has the advantage of being less sensitive to noise because no horizontal derivative is involved. In practice, the current circulating in the power lines is unknown, and we are thus unable to compute the EM field from a given power line. In addition, more than one power line is taken into account. To obtain the secondary field as a result of the ground response, the residual, we remove the long-wavelength component from the estimated amplitude of the $60-\mathrm{Hz}$ field along each flight line. We assume that the sum of the primary fields resulting from each of the power lines varies slowly away from those lines. This is done for each of the measured components of the EM data. The resulting secondary fields are in arbitrary units and cannot be directly converted to conductivity with correct units.

\section{CHIBOUGAMAU SURVEY}

The Chibougamau mining camp is located in northern Quebec, Canada. The first mineralization was discovered in 1870 (Chown et al., 1996), and copper was discovered in 1903. Copper-gold deposits were exploited after a road was completed in 1949. The geology of the area is still being studied as part of government mineral exploration programs, with VMS deposits being the main target. This region, located at the eastern end of the Abitibi Greenstone Belt, is part of the Chibougamau-Matagami Greenstone Belt (Goodwin and Ridler, 1970). Many deposits have been mined in the region. The Lemoine mine (copper-zinc), now closed, was discovered in 1973 as a result of an INPUT Mk V survey flown in 1972 (Keating et al., 2007) for the Quebec Department of Natural Resources.

In 2006, an ATDEM survey was flown on behalf of the Government of Canada. The data were acquired by Fugro Airborne Surveys (Keating et al., 2007) south of Chibougamau, Québec, using a MEGATEM $^{\mathrm{II}}$ system, flown at 200-m line spacing over four different blocks. Several power lines $(735 \mathrm{kV})$ crosscut Block A, shown in Figure 4. The power-line fields were relatively uniform during each flight, and the filtering technique described in the previous section was used to process the raw data collected by the system. We selected the northeast block, denoted by the black box in Figure 3, as our area of study.

In the Chibougamau area, the volcano-sedimentary assemblage has been divided into two groups (Allard et al., 1979; Gobeil and Racicot, 1983): the Roy Group at the base and the Opémisca Group

Power line

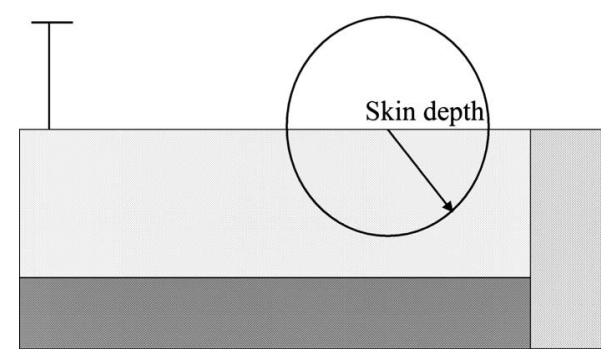

Figure 3. Illustration of the apparent conductivity concept. The penetration of the magnetic field from the power line is assumed to be affected more by the local conductivity than the distance from the source (the power line) or a geologic distance discontinuity. 
at the top. The Roy Group, the only group in the area shown in Figure 5 , includes two volcano-sedimentary cycles subdivided into the Obatogamau (not present in the area), Waconichi, Gilman, Blondeau, and Bordeleau Formations (not present in the area). The Waconichi, located near the bottom in Figure 5, is composed of massive rhyolite and felsic pyroclastics. The Gilman, which hosts the Lac Gwillim and Lac Scott faults, is mostly a sequence of andesitebasalt and comagmatic gabbro and diorite dikes. The Blondeau is mainly composed of rhyolitic and chert tuff, graphitic agillite, and intermediate to felsic lavas. It is injected by mafic sills of the Cummings Complex (Roberge, Venture, and Bourbeau Formations). The volcano-sedimentary rocks contain many intrusions of various compositions. The most important is the Doré Lake Complex, a fourzone stratiform magmatic intrusion. The Chibougamau pluton is of felsic composition. Major structural elements have an east-west schistocity, east-west folds, and east-west and north-east faults.

Figure 6 shows the areas of the mineral occurrences in the study area. Copper $(\mathrm{Cu})$, zinc $(\mathrm{Zn})$, and gold $(\mathrm{Au})$ are the main occurrences, although there is some silver (Ag). A zinc occurrence, circled at the southwest, is the Scott Lake deposit, a small VMS deposit discovered in 1976 following up an ATDEM anomaly. Figure 7 shows the magnetic anomaly map. The Roberge sill has a strong magnetic signature, followed by the Venture sill. The southern part of the survey area has a very quiet magnetic signature.

\section{ATDEM AND POWER-LINE FIELD RESULTS}

The standard procedure (Palacky and West, 1991) for interpreting ATDEM surveys is to locate an anomalous field (usually maxima),

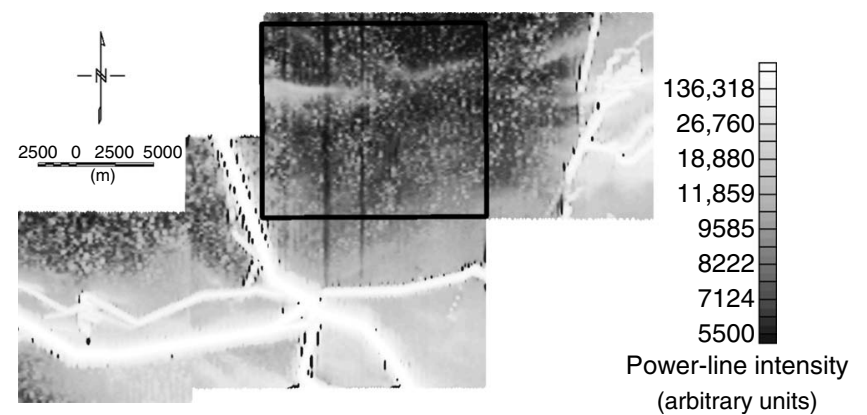

Figure 4. Chibougamau Block A power-line monitor map, showing the power-line fields. The area surrounded by the black box is discussed in the text. Power-line locations are indicated by strong values (white) of the power-line monitor intensity.

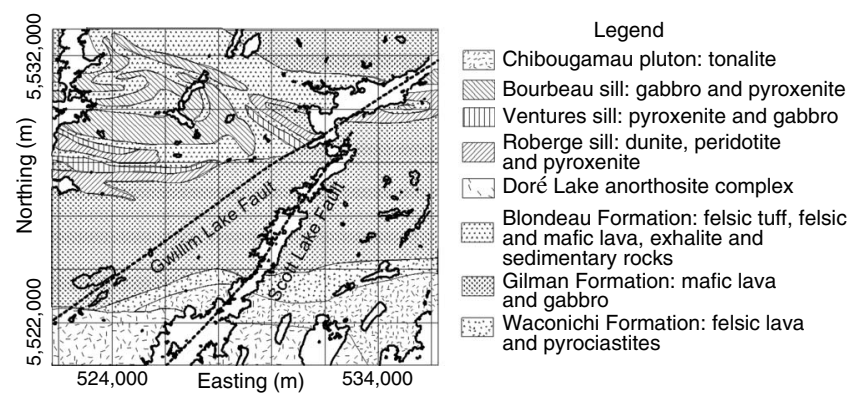

Figure 5. Geologic map of the area of interest; from Gobeil and Raci$\cot (1983)$. fit plate model nomograms to the observed response, and position the anomalies on a map. These anomalies are presented in Figure 8; many are associated with the sills and the Blondeau Formation, which is rich in argillite. A map of the apparent conductance based on a thin-sheet model (Smith, 2000) is shown in Figure 9. The same east-west conductive zones are detected. In addition, conductance anomalies are observed over lakes and are attributed to lake-bottom sediments.

Figure 10 shows the map of the apparent conductivity calculated from the $60-\mathrm{Hz}$ power-line response over the same area using the formula expressed in equations 1 and 2 . In the north-central area of the map, east-west conductive features are displayed. These areas correspond to locations of ATDEM anomalies. More information is shown by the north-south (along lines) and east-west power-line field residuals shown on Figure 11. These residuals, obtained by low-pass filtering, better outline the geology than the computed apparent conductivity. Because these residuals are attributed to local conductors, their presence is enhanced by the resistive background.

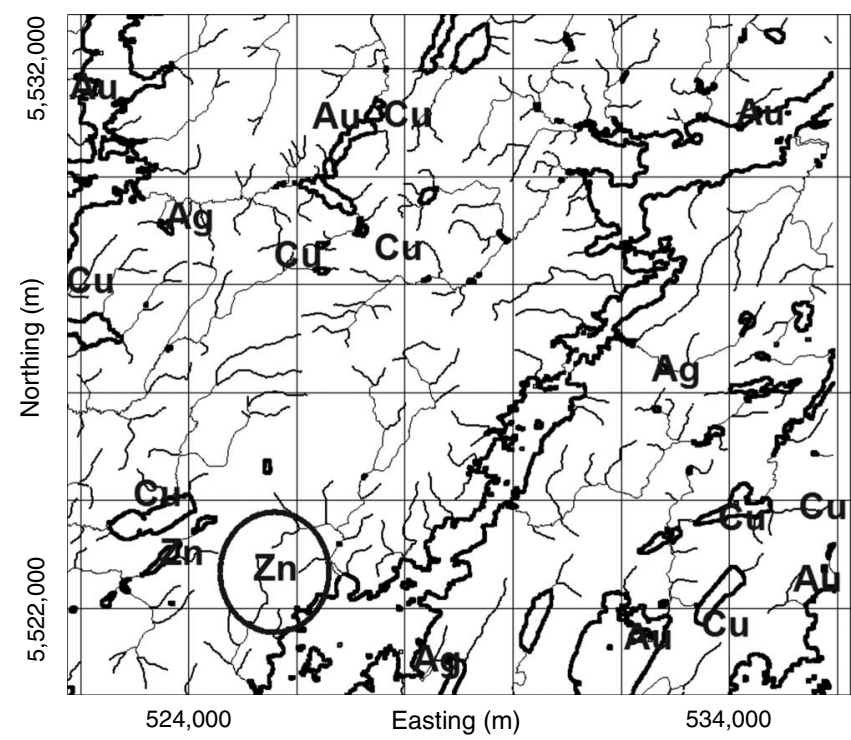

Figure 6. Detailed map of the survey area, showing mineralization occurrences. The location of the Scott deposit is highlighted by a circle. For reference, a 20-km geographic grid is shown in the background. Heavy lines are lake contours; thin lines are rivers.

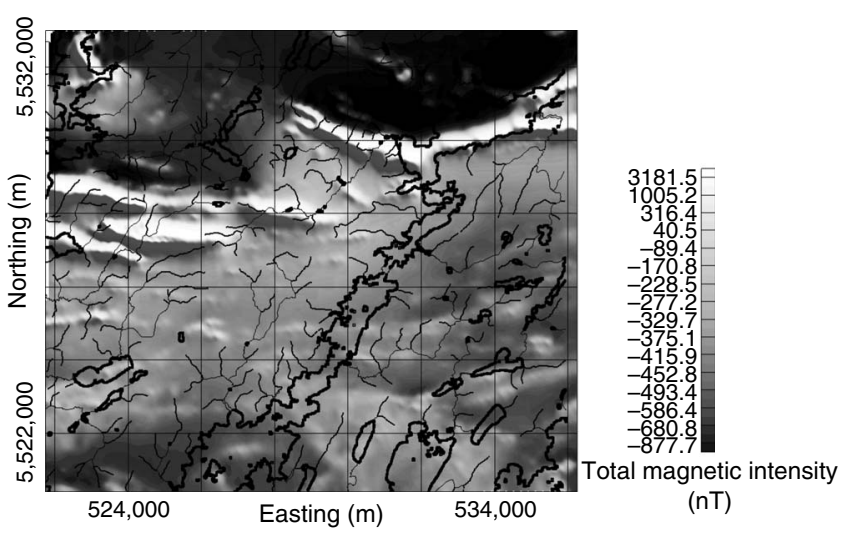

Figure 7. Total-magnetic-intensity map of the area of analysis. 


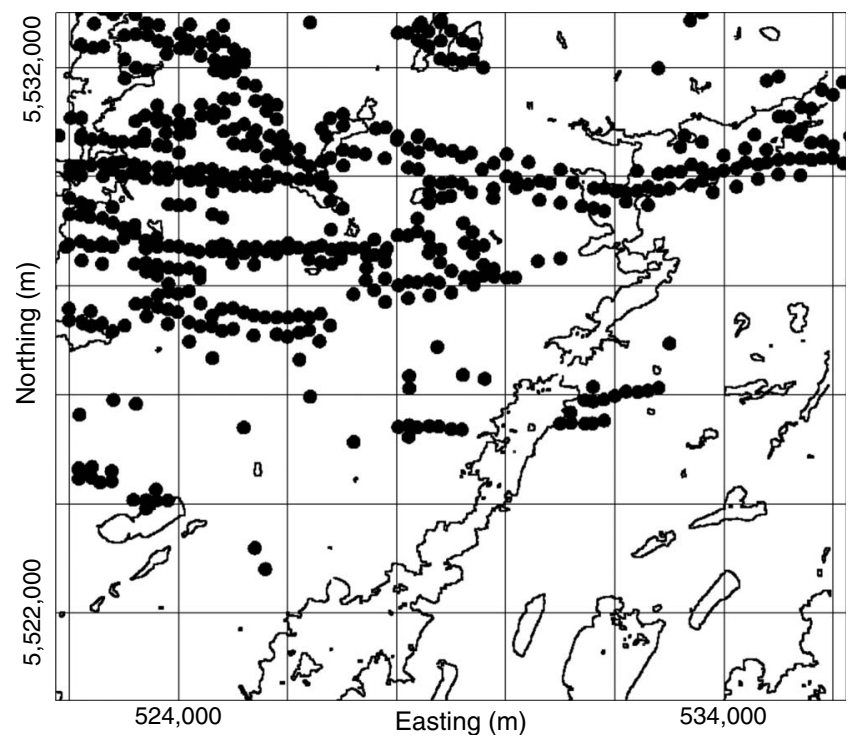

Figure 8. Location of ATDEM anomalies assuming a vertical thinplane model.

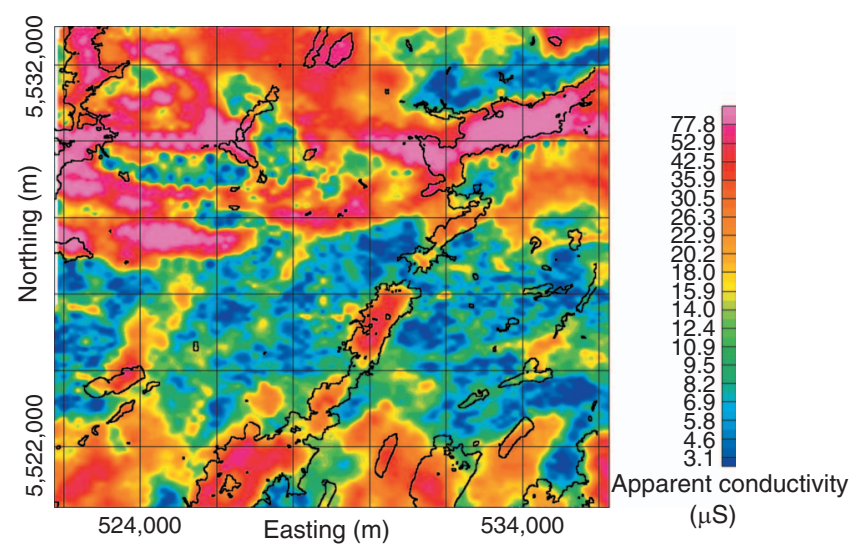

Figure 9. Apparent conductance (horizontal thin-sheet model) estimated from ATDEM measurements.

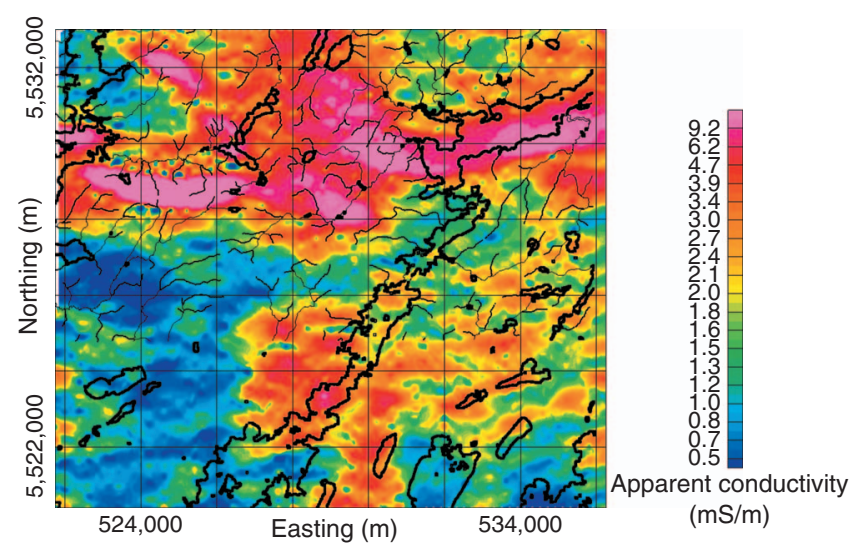

Figure 10. Apparent conductivity (half-space model) estimated from power-line field measurements. a)

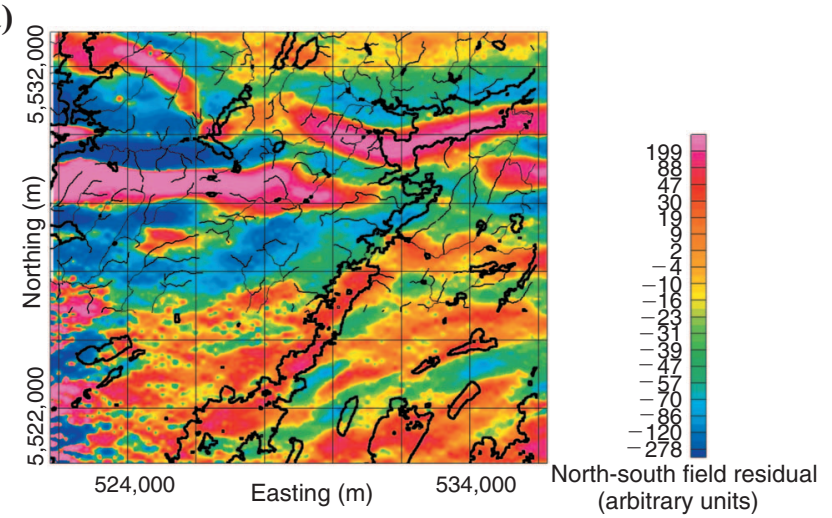

b)

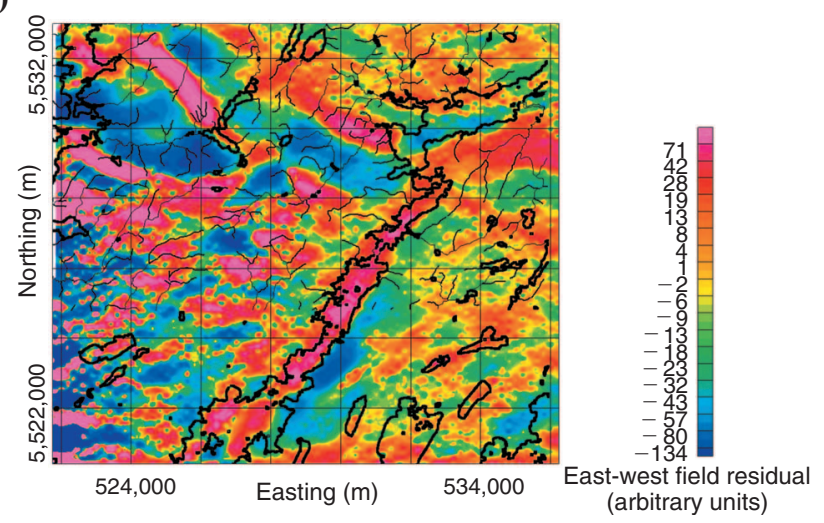

Figure 11. (a) North-south and (b) east-west power-line field residuals.

The long, east-trending conductive features of the Blondeau Formation are detected. However, it is interesting to notice, particularly on the east-west residual, the presence of the Scott Lake fault, a long, schistose fault. The Blondeau Formation conductors, because of their varying geometry, display different north-south and east-west residuals. The Blondeau Formation and sills are detected by magnetic, ATDEM, and power-line fields. Formally, this is not considered a typical VMS environment. But it is a volcanic environment of interest for volcano-exhalative gold exploration. The Blondeau Formation is being explored for gold (Cuvier showing; Houle, 2008, personal communication). Electromagnetic (ATDEM) and magnetic methods complement each other to explore for gold occurrences associated with faulting of the graphitic-volcanic environment.

In the south part along the Waconichi Formation, known as a favorable environment for VMS deposits, exploration relies on ATDEM field geometry. Power-line fields are extraneous. However, they can indicate the location and extent of the Scott Lake fault. They reveal some potential to be more sensitive to the background geology because of the planar field and the low frequency, although we cannot determine the depth of the conductors. Other features on the residual maps might be associated with geology. The method could be refined by quantifying the interpretation.

\section{CONCLUSION}

Our results show that power-line field measurements can bring useful supplementary information to ATDEM surveys. In the survey presented, power-line information highlighted faults and geologic zones less apparent on images produced from ATDEM data. Our re- 
sults show a potential benefit in acquiring power-line field measurements in parallel to ATDEM in areas where the fields can be collected. For the Chibougamau survey, these fields present supplementary information that can be useful in geologic interpretation of the ATDEM data. Even if a survey is not designed to map conductivity using power-line fields, useful geologic information can be extracted from power-line fields and can help locate new mineral occurrences.

\section{ACKNOWLEDGMENTS}

The ATDEM data were graciously provided by the Geological Survey of Canada, Natural Resources Canada. The overlay geology was obtained from the Ministère des Ressources Naturelles et de la Faune of Québec. Fugro Airborne Surveys supported this research and allowed publication of the results. We acknowledge Jean Lemieux and Patrick Houle for fruitful discussions. We also acknowledge Victor Labson, Yonghe Sun, and an anonymous reviewer for helpful suggestions.

\section{REFERENCES}

Allard, G. O., J.-L. Caty, E. H. Chown, J. Cimon, A. Gobeil, and D. Baker, 1979, Stratigraphy and metallogeny in the Chibougamau area: Annual Meeting, Geological Association of Canada, Field Trip B-1.

Boldy, J., 1979, Exploration discoveries, Noranda district, Quebec (Case history of a mining camp), in P. J. Hood, ed., Geophysics and geochemistry in the search for metallic ores: Geological Survey of Canada Economic Geology Report 31, 593-603.
Chown, E. H., R. Daigneault, W. Mueller, and P. Pilote, 1996, Environnement géologique de l'extrémité orientale de la sous-province de l'Abitibi, in P. Pilote, C. Dion, and R. Morin, eds., Géologie et évolution métallogénique de la région de Chibougamau: Des gîtes de type $\mathrm{Cu}-\mathrm{Au}-\mathrm{Mo}$ porphyriques aux gisements filoniens mésothermaux aurifères: Ministère des Ressources Naturelles, Gouvernement du Québec, MB 96-14, 1-31.

Gibson, H. L., R. L. Allen, G. Riverin, and T. E. Lane, 2007, The VMS model: Advances and application to exploration targeting: 5th Decennial International Conference on Mineral Exploration, Proceedings, 713-730.

Gobeil, A., and R. Racicot, 1983, Carte lithostatigraphique de la région de Chibougamau: Ministère de l'Énergie et des Ressources, Gouvernement du Québec, MM 83-02.

Goodwin, A. M., and R. H. Ridler, 1970, The Abitibi orogenic belt, in E. J. Baer, ed., Symposium on basins and geosynclines of the Canadian Shield: Geological Survey of Canada Study 70-40, 1-30.

Keating, P., R. Dumont, and P. Houle, 2007, A comparison between old and recent airborne time-domain electromagnetic surveys flown in the Chibougamau region, eastern Canada: 5th Decennial International Conference on Mineral Exploration, Proceedings, 863-867.

Labson, V. F., and H. G. Medberry, 1989, Airborne resistivity mapping using powerline sources: 59th Annual International Meeting, SEG, Expanded Abstracts, 138-140.

Martin, L., and M. Masson, 2005, Towards new discoveries thanks to the application of 3D modeling in the Noranda Camp: Québec Exploration 2005, Program with Abstracts, 14

Palacky, G. J., and G. F. West, 1991, Airborne electromagnetic methods, in M. N. Nabighian, ed., Electromagnetic methods in applied geophysics: Application: SEG, 811-879.

Schmucker, U., 1973, Regional induction studies: A review of methods and results: Physical Earth Planetary International, 7, 365-378.

Smith, R. S., 2000, The realizable resistive limit: A new concept for mapping geological features spanning a broad range of conductances: Geophysics, 65, 1124-1127.

Smith, R. S., D. Fountain, and M. Allard, 2003, The MEGATEM fixed-wing transient EM system applied to mineral exploration: A discovery case history: First Break, 21, 73-77. 